\title{
Presença de Salmonella em frangos de corte aparentemente sadios em unidades de criação industrial na região de São José do Vale do Rio Preto - RJ*
}

\author{
Salmonella of seemed-to be healthy poultry of industrial breeding \\ units in São José do Rio Preto - RJ
}

\author{
Virginia Léo de A. Pereira, ${ }^{*}$ Gicélia Maria da Silva, ${ }^{* \star}$ Mosar Lemos ${ }^{\star}$
}

\begin{abstract}
Resumo
Um pequeno número de aves infectadas por Salmonella pode contaminar todo o processo de abate, comprometendo o produto final e constituindo um grave fator de risco nas toxinfecções alimentares em humanos. Este trabalho tem por objetivo detectar a presença de Salmonella em frangos de corte aparentemente sadios, investigando a ave viva. Em uma amostragem de 106 frangos de corte em quatro unidades de criação industrial, na região de São José do Vale do Rio Preto, no Estado do Rio de Janeiro, realizou-se o teste de Soroaglutinação Rápida em Placa (SAR) com sangue, e foi coletado material fecal através de swabs de cloaca, processados no Laboratório de Ornitopatologia da UFF. Apesar de nenhuma ave ter sido reagente ao teste de SAR, foram isoladas 3 cepas $(2,83 \%)$ de Salmonella enteritidis a partir dos swabs. As três aves positivas pertenciam à mesma unidade de criação. A diferença observada entre as unidades trabalhadas caracterizou-se pelo piso de terra batida nos galpões da unidade que apresentou aves positivas, ao contrário das unidades negativas, onde o piso era de cimento, mas não foram analisadas as condições de tratamento e higiene das unidades.
\end{abstract}

Palavras-chave: Salmonella; Salmonella enteritidis, frangos de corte; isolamento

\section{Introdução}

A salmonelose é uma infecção causada por bactérias do gênero Salmonella, pertencentes à família Enterobacteriaceae, capazes de acometer uma grande variedade de animais de sangue quente e sangue frio.

Hoje são conhecidas duas espécies de Salmonella ( $S$. entericae $S$. bongori), englobando mais de 2300 sorovares que só recentemente foram reconhecidos como sorovares, sendo tratados antes como espécies. Por sua familiaridade a clínicos e bacteriologistas, os nomes mais comuns na designação dos sorovares da subespécie enterica, espécie enterica foram mantidos, em detrimento do uso da fórmula antigênica como são designados os sorovares de outras subespécies de Salmonella enterica e S. bongorie de outras espécies bacterianas. Assim, por exemplo, a Salmonella enterica enterica sorovar typhimurium pode ser designada apenas Salmonella typhimurium (Popoff e Le Minor, 1992).
Para a indústria avícola são muito importantes a S. pullorum e a $S$. gallinarum por sua especificidade de hospedeiro. Apesar de todos os esforços e desenvolvimento no controle desses sorovares, ainda trazem prejuízos em muitos países (Silva, 1996 ; Bezerra, 1995).

As Infecções Paratifóides Aviárias, como as causadas por $S$. enteritidis e $S$. typhimurium, também comprometem as produções avícolas com grandes perdas econômicas, além de terem grande significado em Saúde Pública. Estas bactérias e outras do grupo paratifóide são mais difíceis de controlar devido a sua complexa epidemiologia, envolvendo transmissão vertical, excreção fecal, contaminação do ambiente e existência de reservatórios de diferentes espécies (Barrow, 1993; Bezerra, 1995). A Salmonella enteritidis pode infectar um lote de aves invadir lotes vizinhos sem apresentar nenhum sintoma de doença. Esta infecção inaparente não se limita ao intestino, estendendo-se também aos órgãos internos, incluindo o sistema reprodutivo, com conseqüente contaminação da progênie ou de ovos comerciais para consumo humano (Lozano, 1996).

\footnotetext{
*Dissertação para obtenção do título de mestrado em Medicina Veterinária da acadêmica Virginia Løo de A. Pereira.

**Médicos Veterinários, alunos do curso de Mestrado em Medicina Veterinária; área: Patologiä; subárea: Ornitopatologia; Faculdade de Veterinária (UFF).

***Professora da disciplina de Ornitopatologia, do Departamento de Patologia e Clínica Veterinária e do mestrado em Medicina Veterinária; subárea Ornitopatologia, na Faculdade de Veterinária (UFF), Rua Vital Brazil Filho, 64, Niterói, RJ, Brasil, CEP 24230-340.
} 
Na maioria dos surtos que ocorrem em seres humanos, a fonte original alimentar que os provocou não é determinada, principalmente porque o material a partir do qual poderiam ser feitas as culturas, normalmente, não é recuperado. Nos casos onde a fonte de contaminação é determinada, a carne de aves e os ovos são importantes veículos de infecção. Portanto, é essencial que infecções por Salmonella na ave viva sejam controladas (Hinton, 1992).

Giorgi (1972) e Nascimento (1996) mencionam que um número pequeno de aves contaminadas levadas ao abatedouro pode vir a contaminar toda a linha de abate, comprometendo a qualidade do produto final.

O sucesso no controle da Salmonella na indústria avícola está diretamente relacionado à elaboração e execução de um programa de controle integral e aplicável, dirigido e realizado em todos os níveis da cadeia de produção, tais como: fábrica de ração, reprodutoras, incubatórios, granjas de produção comercial, abatedouros, manejo do produto acabado, incluindo a cozinha da dona de casa (Hinton, 1992 ; Lozano, 1996).

O presente trabalho tem como objetivo estudar a presença de Salmonella em frangos de corte vivos, que não apresentavam sinais clínicos de doença, na região de São José do Vale do Rio Preto, no Estado do Rio de Janeiro. Esta região é bastante significativa para a avicultura industrial do estado, concentrando grande parte da criação de frangos de corte e toda a produção de ovos comerciais e pintos de um dia.

\section{Material e métodos}

\section{Origem das aves estudadas}

Foram estudadas amostras (sangue da asa e swabs cloacais) provenientes de 106 frangos de corte, aparentemente sadios, escolhidos ao acaso, de unidades de criação industrial de quatro empresas avícolas na região de São José do Vale do Rio Preto, no Estado do Rio de Janeiro.

As unidades de criação trabalhadas foram identificadas como unidades A, B, C e D (Quadro 1). As quatro unidades utilizavam o mesmo sistema de criação com equipamentos similares. Todas estavam equipadas com bebedouros e comedouros pendulares, com o mesmo sistema de cortinas, exceto a unidade A, que usava comedouro automático.

No tratamento de pintinhos, todos os equipamentos eram iguais: comedouros tipo sifão, bebedouros pendulares e campânulas a gás.

As quatro unidades utilizavam cama de maravalha. O piso dos galpões na unidade $B$ era constituído de terra batida. Nas demais unidades, os galpões eram cimentados.
Quadro 1: Unidades de criação, idade das aves e no de aves estudadas

\begin{tabular}{c|c|c|c}
$\begin{array}{c}\text { Unidades de } \\
\text { producão }\end{array}$ & $\begin{array}{c}\text { Idade das } \\
\text { aves (dias) }\end{array}$ & $\begin{array}{c}\text { Node aves } \\
\text { trabalhadas }\end{array}$ & $\begin{array}{c}\text { Total de } \\
\text { aves/unidade } \\
\text { de produção }\end{array}$ \\
\hline A & 06 & 11 & 26 \\
\hline B & 25 & 15 & 25 \\
\hline C & 35 & 10 & 25 \\
& 20 & 15 & \\
\hline D & 39 & 10 & 30 \\
\hline Total de aves trabalhadas & 10 & \\
\hline
\end{tabular}

Fonte: Empresas avícolas na região de São José do Vale do Rio Preto, RJ, 1996.

\section{Coleta das amostras e teste de soroaglutinação rápida (SAR)}

\section{Coleta de fezes}

Todas as aves foram submetidas à coleta de material fecal através da introdução de swabs na cloaca, acondicionados em meio de transporte Cary e Blair (Difco), para posterior processamento laboratorial.

\section{Teste de soroaglutinação rápida (SAR)}

Imediatamente após a coleta de material fecal, os 106 animais foram sangrados e testados pelo método de soroaglutinação rápida, com antígeno comercial Pulor Teste (Bio Vet) na própria unidade de criação. Foram utilizadas duas gotas de sangue para uma gota de antígeno, em placa de vidro limpa, com observação da formação ou não de aglutinação por um período não superior a 2 minutos, comparando a reação com os controles positivo e negativo.

\section{Isolamento e identificação de Salmonella}

As fezes contidas nos swabs cloacais foram analisadas no Laboratório de Ornitopatologia da Faculdade de Medicina Veterinária da Universidade Federal Fluminense, utilizando metodologia recomendada pelo Laboratório de Enterobactérias do Departamento de Bacteriologia do Instituto Oswaldo Cruz (Costa e Hofer, 1972).

\section{Pré-enriquecimento}

Os swabsacondicionados em meio Cary e Blair foram transferidos para tubos contendo $10 \mathrm{ml}$ de água peptonada a $1 \%$ tamponada e incubados por 18 horas a $37^{\circ} \mathrm{C}$. 


\section{Enriquecimento}

Foram utilizados os caldos tetrationato (Difco) e RappaportVassiliadis (Oxoid), distribuídos em alíquotas de $10 \mathrm{ml} \mathrm{em}$ tubos de ensaio esterilizados. Um inóculo de $1 \mathrm{ml}$ do crescimento em água peptonada foi transferido para caldo tetrationato, incubado por $24 \mathrm{~h}$ a $37^{\circ} \mathrm{C}$ e $0,1 \mathrm{ml}$ do crescimento em água peptonada, para caldo RappaportVassiliadis, incubado por $24 \mathrm{~h} \mathrm{a} 42^{\circ} \mathrm{C}$.

\section{Plaqueamento}

Foram empregados os meios seletivos-indicadores: ágar eosina-azul de metileno Levine (Difco), ágar SalmonellaShigella (Merck), e verde brilhante (BBL), distribuídos em placas de Petri (13ml/placa), semeadas com os crescimentos dos caldos de enriquecimento e incubadas a $37^{\circ} \mathrm{C}$ por 24h.

\section{Identificação bioquímica presuntiva}

De 3 a 5 colônias sugestivas de Salmonella, obtidas nos meios seletivo-indicadores, foram repicadas para tubos contendo o meio de triagem Costa e Vernin, e incubados a $37^{\circ} \mathrm{C}$ por $24 \mathrm{~h}$. Após este período, procedeu-se a uma identificação presuntiva que permite uma análise do comportamento bacteriano através das reações de motilidade, ação sobre a lactose e/ou a sacarose, produção de gás, produção de gás sulfídrico (H2S), ação da urease e produção do indol (Costa e Hofer, 1972 ; Magalhães, 1986).

\section{Caracterização bioquímica}

A análise bioquímica das amostras compatíveis com Salmonella foi realizada através da utilização do Sistema API $20 \mathrm{E}$ (Bio-Mérieux), incubado a $37^{\circ} \mathrm{C}$ por $24 \mathrm{~h}$. Em caso de dúvidas na interpretação da leitura das provas, fez-se a confirmação e/ou complementação com as seguintes provas bioquímicas: oxidase, indol, descarboxilação da lisina, fermentação da sacarose, triptofano desaminase (TDA), cianeto de potássio (KCN), oxidação-fermentação da glicose (OF).

\section{Manutenção das amostras}

As amostras selecionadas compatíveis com Salmonella foram mantidas em frascos de vidro com rolha de borracha, contendo ágar simples fosfatado, e enviadas para sorologia no Laboratório de Enterobactérias do Instituto Oswaldo Cruz.

\section{Sorotipificação}

A caracterização antigênica das bactérias foi realizada pelo Laboratório de Enterobactérias, da Fundação Oswaldo Cruz, que utilizou a técnica de Aglutinação Rápida em Placa, identificando os sorovares de Salmonella de acordo com o Esquema de Kauffmann-White, segundo Popoff e Le Minor (1992).

\section{Resultados e discussão}

\section{Coleta de fezes}

Na presente pesquisa foi eleito o swab de cloaca como meio de coleta de fezes, pela necessidade de identificar as aves trabalhadas para correlacionar o resultado do isolamento bacteriológico ao obtido no teste de SAR com sangue das mesmas aves. Isso não seria possível com a coleta de fezes frescas. Higgins et al. (1981) consideraram fezes frescas melhores indicadores e espécimens mais confiáveis que o swabcloacal. Nagaraja, Pomeroy e Williams (1991) citam a coleta com a utilização do swab de cloaca na ave viva como melhor, onde não há sacrifício das aves, concordando com a metodologia empregada neste trabalho, uma vez que foram pesquisadas aves aparentemente sadias.

\section{Teste de Soroaglutinação Rápida (SAR)}

O teste de SAR teria eficiência para detecção de aves reagentes não só para S. pullorum e S. gallinarum, como para outros sorovares, inclusive $S$. enteritidis, de acordo com Snoyenbos (1981), Waltman e Horne (1993), Lozano (1996). Entretanto, neste trabalho não foram detectadas aves suspeitas pela SAR (Tabela 1), apesar de termos obtido isolamento de $S$. enteritidis na unidade $\mathrm{B}$, como demonstram as Tabelas 2 e 3. Waltman e Horne (1993).

Tabela 1: Resultado de SAR em frangos de corte em 04 unidades de criação na região de São José do Vale do Rio Preto, RJ

\begin{tabular}{|ccc|}
\hline Unidade & $N^{\circ}$ aves testadas & Aves positivas \\
\hline A & 26 & 0 \\
B & 25 & 0 \\
C & 25 & 0 \\
D & 30 & 0 \\
\hline Total & 106 & 0 \\
\hline
\end{tabular}

mencionam a possibilidade de falso-negativos, recomendando o teste em grande número de aves ou com repetições. Em frangos de corte se torna uma prática difícil testar as aves em muitas ocasiões, por questões como o stress, afetando o desempenho do lote, e o seu breve período de vida. Gast e Beard (1990) encontraram diferenças nos resultados de detecção de resposta sorológica com provas de aglutinação, relacionadas ao uso de antígeno $S$. pullorum e antígeno $S$. enteritidis, em poedeiras comerciais infectadas com S. enteritidis. O antígeno S. enteritidis apresenta maior sensibilidade. Os mesmos autores alertam para os problemas de baixa sensibilidade, com a obtenção de resultados falso-negativos; ou inadequada especificidade com respostas positivas para outros sorovares de Salmonella ou outras enterobactérias, reco- 
Tabela 2: Isolamento de Salmonella em frangos de corte em 04 unidades de criação na região de São José do Vale do Rio Preto-RJ

\begin{tabular}{ccc} 
Unidades & Isolamento & $\%$ \\
\hline A & $0 / 26^{\star}$ & 0,00 \\
B & $3 / 25$ & 12,00 \\
C & $0 / 25$ & 0,00 \\
D & $0 / 30$ & 0,00 \\
\hline Total & $3 / 106$ & 2,83 \\
\hline
\end{tabular}

${ }^{*} \mathrm{~N}$ ㅇ de resultados positivos sobre o total de aves estudadas.

mendando o uso dos dois antígenos. No Brasil, não existe antígeno comercial disponível para SAR com S. enteritidis. Gast e Beard (1990) também registram que outra possibilidade na ocorrência de resultados falso-negativos na SAR seria a infecção estar-se mantendo a nível entérico na ave, sem infecção sistêmica, dificultando a resposta imune humoral e, conseqüentemente, a detecção pela sorologia.

As monitorias dos lotes não devem ser baseadas apenas nos exames sorológicos, pois eles podem apresentar faIhas na detecção da infecção. Programas de prevenção e monitoria adotados em granjas devem ser direcionados para o isolamento, podendo ser complementado com sorologia. $\mathrm{O}$ isolamento prevê a pesquisa em cama, fezes frescas, swab de cloaca, swab de arrasto, água, ração, entre outros (Berchieri Jr. e Barrow, 1995). Higgins et al. (1981)

Tabela 3: Resultado de isolamento de Salmonella em frangos de corte na unidade $B$, segundo a idade, na região de São José do Vale do Rio Preto, RJ

\begin{tabular}{|ccc|}
\hline Idade (dias) & Isolamento & $\%$ \\
23 & $2 / 10^{*}$ & 20,00 \\
35 & $1 / 15$ & 6,66 \\
Total & $3 / 25$ & 12,00 \\
\hline
\end{tabular}

*№ de resultados positivos sobre o total de aves estudadas.

fizeram um estudo em nove lotes de frangos em nove granjas, analisando poeira, água, cama, fezes frescas e ração. Detectaram a contaminação em oito dos nove lotes trabaIhados. Goren (1995) descreve as medidas tomadas após a descoberta de surtos de $S$. enteritidis na Holanda, de 1989 a 1995, e registrou que a partir de 1989 até 1992 todos os lotes de reprodutoras foram monitorados por exames bacteriológicos de fezes, uma vez que todos os métodos e testes sorológicos em placa, de microaglutinação e ELISA, não se mostraram suficientemente sensíveis ou específicos para detectar infecções por S. enteritidis.

\section{Isolamento e identificação}

O procedimento para isolamento de Salmonella, realizado no Laboratório de Ornitopatologia da UFF, seguiu a orien- tação do Laboratório de Enterobactérias da Fiocruz, com base também nas orientações da maioria dos trabalhos pesquisados sobre o assunto, e mostrou-se eficiente, obtendo resultado positivo em $12,00 \%$ das amostras trabaIhadas na unidade B (Tabela 3 ) e 2,83\% do total de aves tomadas como amostra (Tabela 2).

O isolamento de Salmonella em $2,83 \%$ das aves analisadas é compatível com o resultado obtido por Giorgi (1972), que trabalhou com fezes de aves aparentemente sadias na entrada do abatedouro e obteve $2,6 \%$ de isolamentos. De outro modo, Delazari (1989) cita percentuais maiores de isolamentos em frangos em vários países, no período de 1970 a 1978 . Hofer (1977) obteve $5,44 \%$ de isolamentos positivos em 2.959 culturas trabalhadas. Silva (1978), trabalhando com embriões de galinhas e perus reprodutores, encontrou $6,00 \%$ de amostras positivas para Salmonella. Silva (1981) cita $3,4 \%$ de isolamentos positivos em 2.047 casos suspeitos de salmonelose em aves, estudados entre 1975 e 1980, em Belo Horizonte.

\section{Sorotipificação}

Giorgi (1972) identificou 7 sorovares diferentes em seus isolamentos, mas não isolou $S$. enteritidis em nenhuma das aves trabalhadas. Costa et al. (1996) identificaram 10 sorovares diferentes em 150 amostras de carne de frango colhidas em abatedouro, onde predominou o isolamento de S. enteritidis. Navarro (1995) afirmou que os isolamentos de $S$. enteritidis passaram a ser encontrados mais comumente na avicultura comercial a partir de 1980 e citou isolamentos no Brasil a partir de 1989.

Considerando que um pequeno número de aves contaminadas pode comprometer toda a linha de abate, afetando o produto final (Giorgi, 1972; Nascimento, 1996), este trabalho adquire grande importância do ponto de vista sanitário, porque o resultado de $2,83 \%$ de aves com presença de Salmonella enteritidis pode ser bastante significativo em termos econômicos e de saúde pública.

Das quatro unidades de criação industrial trabalhadas, apenas na unidade $B$ foi obtido isolamento positivo. Considerando-se que esta é a única unidade que não possui piso cimentado nos galpões e maior teor de umidade na cama, este pode ser um dos fatores que favorece o aparecimento de Salmonella em frangos de corte, concordando com Carr et al. (1995).

Não se chegou a avaliar as condições de limpeza e desinfecção dos galpões das unidades de produção estudadas. Davies e Wray (1995) observaram muitos problemas com métodos de desinfecção em unidades industriais de aves naturalmente infectadas com $S$. enteritidis, principalmente no que diz respeito à eficiência na utilização dos desinfetantes. Os mesmos autores, em 1996, realizaram um estudo em galpões de reprodutoras pesadas antes e depois da limpeza e desinfecção, observando que nenhuma das granjas analisadas eliminou a S. enteritidis do ambiente dos galpões. 
A pesquisa da presença de Salmonella, seja nas aves, seja no ambiente, vem-se tornando cada vez mais importante como instrumento para avaliação da situação no que diz respeito à contaminação por este microrganismo e o estabelecimento de medidas de controle eficazes.

\section{Conclusões}

A metodologia empregada permitiu detectar a presença de Salmonella enteritidis em frangos de corte a partir de swabs de cloaca.
O resultado negativo do teste de SAR com antígeno Pullorum/Gallinarum foi compatível com a ausência de isolamentos para S. pullorum e S. gallinarum.

O teste de SAR não deve ser utilizado como única prova de triagem de aves portadoras de Salmonella.

O antígeno comercial Pullorum/Gallinarum não foi eficiente na detecção de $S$. enteritidis.

A identificação de sorovares de Salmonella em isolamentos de amostras de aves é um importante instrumento de vigilância epidemiológica.

\begin{abstract}
A small amount of infected chicken by Salmonella may affect all the process of slaughter, endangering the processed products and constituting a serious factor of risk in food-poisoning for human beings. The aim of this work was to detect the presence of Salmonella in a apparently healthy broiler chicken by investigating them alive. In a sampling of 106 broiler-chicken of four poultry units in the area of São José do Vale do Rio Preto, in Rio de Janeiro State, the S.A.R test was done and cloacal swabs were collected and processed at the Fluminense Federal University Ornithopathology Laboratory. Although no broiler-chicken has reacted to the S.A.R. test, $3(2,83 \%)$ strains of the Salmonella enteritidis were isolated. The 3 positive broiler-chicken belonged to the same poultry unit. The difference observed in the poultry units of this work was the earthen floor in the broiler houses in the positive unit opposit to the negative units, where the floor was cemented. No hygienie and tratement conditions in these units were analysed in this study.
\end{abstract}

Keywords: poultry; industrial breeding units; Samonella.

\title{
Agradecimentos
}

Ao Dr. Claude André Solari, pesquisador responsável pelo Laboratório de Enterobactérias do Departamento de Bacteriologia da Fiocruz, e toda a sua equipe, pela sorotipificação das amostras e ajuda no desenvolvimento da pesquisa.

À Dra. Helena Magalhães e toda a equipe do Laboratório de Biologia Animal, área de bacteriologia da Pesagro, pelo apoio prestado durante toda a execução do trabalho

Ao Dr. Dalton G. de Mattos Júnior, professor adjunto IV da disciplina de Doenças Parasitárias do curso de pós-graduação em Medicina Veterinária da Universidade Federal Fluminense, pelo seu auxílio na redação deste trabalho.

\section{Referências bibliográficas}

BARROW, P. A. Salmonella control - past, present and future. Avian Pathology, v. 22, p. 651-669, 1993.

BERCHIERI Jr. A., BARROW, P. A. Patologia e métodos de diagnóstico de SE em aves. In: CONFERÊNCIA APINCO 95 DE CIÊNCIA E TECNOLOGIA AVÍCOLAS, 1995, Curitiba. Anais...Campinas : Associação dos Produtores de Pintos de Corte, 1995. 148 p., p. 1-5.

BEZERRA, R.. Recuperação e pesquisa de Salmonella spp e detecção de anticorpos em ovos comerciais de galinha Gallus gallus (Linnaeus, 1758). São Paulo, 1995. 59 p. Tese (Mestrado) - Universidade de São Paulo.

CARR, L. E. et al. Prevalence of Salmonella in broiler flocks: of litter water activity, house construction, and watering devicès. Avian Diseases, Georgia, v. 39, p. 39-44, 1995.

COSTA, G. A., HOFER, E. Isolamento e identificação de enterobactérias. Rio de Janeiro, 1972. 120 p. Monografia Instituto Oswaldo Cruz.
COSTA, F. N., ROSSI, O. D., TAVECHIRO, A. T. Sorotipos de Salmonella isolados de carcaças e cortes de frango, Jaboticabal, 1996. In: TRABALHOS DE PESQUISA - CONFERÊNCIA APINCO 1996 DE CIÊNCIA E TECNOLOGIA AVÍCOLAS. 1996, Curitiba. Anais... Campinas : Associação dos Produtores de Pintos de Corte, 1996. 106 p., p. 57.

DAVIES, R. H., WRAY, C. Observations on desinfection regimens used on Salmonella enteritidis infected poultry units. Poultry Science, v. 74, p. 638-647, 1995.

DAVIES, R. H., WRAY, C. Studies of contamination of three broiler breeder houses with Salmonella enteritidis before and after cleasing and desinfection. Avian Disease, Georgia, v. 40, p. 626-633, 1996.

DELAZARI, I. Controle microbiológico da carne de frango e seus derivados: padrões e exigências para o mercado interno e externo. In: CONFERÊNCIA APINCO 89 DE CIÊNCIA E TECNOLOGIA AVÍCOLAS. 1989, Campinas. Anais...Campinas : Associação dos Produtores de Pintos de Corte, 1989. 75 p., p. 33-42. 
GAST, R. K., BEARD, C. W.Sorological detection of experimental Salmonella enteritidis infections in Laying Hens. Avian Diseases, Georgia, v. 34, p. 721-728, 1990.

GIORGI, W. Animais domésticos como portadores de salmonelas: significado epidemiológico e sua relação com saúde pública. 1972, São Paulo, 55 p. Tese (Doutorado) - Instituto de Ciências Biomédicas - Universidade de São Paulo.

GOREN, E. Experiências com controle de $S$. enteritidis na Holanda de 1989-1995. In: CONFERÊNCIA APINCO 95 DE CIÊNCIA E TECNOLOGIA AVÍCOLAS, 1995, Curitiba. Anais...Campinas : Associação dos Produtores de Pintos de Corte, 1995. 148 p., p. 143-149.

HIGGINS, R. et al. Studies on the dissemination of Salmonella in nine broiler-chicken flocks. Avian Diseases, v. 26, n. 4., p. 26-33, 1981.

HINTON, M. Salmonella infections in poultry and their control. In: CONFERENNCIA APINCO 92 DE CIÊNCIA E TECNOLOGIA AVÍCOLAS, 1992, Santos. Anais... Campinas : Associação dos Produtores de Pintos de Corte, 1992. 274 p., p.119-122.

HOFER, E. Sorotipos de Salmonella identificados pelo Centro Nacional de Salmonella em 1976. In: CONGRESSO BRASILEIRO DE MICROBIOLOGIA, 8, 1977, Rio de Janeiro. Anais...Rio de Janeiro : Sociedade Brasileira de Microbiologia, 1977, p. 92.

LOZANO, F. Uso de uma bacterina contra Salmonella enteritidis como parte integral de um programa de controle na indústria avícola. In: SIMPÓSIO TÉCNICO DE PRODUÇÃO DE OVOS - APA, 6., 1996, São Paulo. Anais...São Paulo : Associação Paulista de Avicultura, 1996. 134 p., p. 107-126.

MAGALHÃES, H. Biotipos, resistência a antimicrobianos e lisotipos em amostras de Salmonella dublin, isoladas de bovinos do município de Cantagalo/RJ. Itaguaí, 1986. $61 \mathrm{p}$. Tese (Mestrado) - Universidade Federal Rural do Rio de Janeiro.

NAGARAJA, K. V., POMEROY, B. S., WILLIAMS, J. E. Paratyphoid infections. In: CALNEK, B. W. et al. Diseases of poultry, 9. ed., lowa : lowa State University Press, 1991, 929 p., Cap. 3, p. 99-129.
NASCIMENTO, V. P. Salmoneloses paratíficas: uma revisão e situação atual. In: SIMPÓSIO TECNICO DE PRODUÇÃO DE OVOS - APA, 6, 1996, São Paulo. Anais...São Paulo : Associação Paulista de Avicultura, 1996. 134 p., p. 93-116.

NAVARRO, M. P. Infecção por Salmonella enteritidis em reprodutoras pesadas na América Latina. In: CONFERÊNCIA APINCO 95 DE CIÊNCIA E TECNOLOGIA AVÍCOLAS, 1995, Curitiba. Anais...Campinas : Associação dos Produtores de Pintos de Corte, 1995. 148 p., p. 7-16.

POPOFF, M. Y., Le MINOR, L. Antigenic formulas of the Salmonella sorovars, 6 . ed., WHO Collaborating centre for reference and research on Salmonella. Institute Pasteur, Paris, 1992.

SILVA, E. N. Salmonelas em galinhas e perus reprodutores de criação industrial, São Paulo, 1978, 91 p. Tese (Doutorado) - Instituto de Ciências Biomédicas da Universidade de São Paulo.

SILVA, E. N. Salmonella enteritidis em avicultura. o que de prático podemos fazer? In: CONFERÊNCIA APICO 96 DE CIÊNCIA E TECNOLOGIA AVÍCOLAS, 1996, Curitiba. Anais... Campinas : Associação dos Produtores de Pintos de Corte, 1996. 210 p., p. 207-210.

SILVA, J. M. L., Salmonelose na indústria avícola brasileira - a ameaça do Tifo Aviário. In: PRODUÇÃO E QUALIDADE DE PINTOS DE UM DIA, 1981, Brasília.. Anais...Belo Horizonte: Universidade Federal de Minas Gerais, 1981. 362 p., p. 319-330.

SNOYENBOS, G. H. Salmonelose aviária: epidemiologia e situação atual no mundo. In: PRODUÇÃO E QUALIDADE DE PINTOS DE UM DIA, 1981, Belo Horizonte. Anais... Belo Horizonte : Universidade Federal de Minas Gerais, 1981. 362 p., p. 305-309.

SNOYENBOS, G. H. Novas técnicas para controle de salmonelas a nivel de granjas. In: PRODUÇÃO E QUALIDADE DE PINTOS DE UM DIA, 1981, Belo Horizonte. Anais... Belo Horizonte : Universidade Federal de Minas Gerais, 1981. 362 p., p. 353-362.

WALTMAN, W. D., HORNE, A. M. Isolation of Salmonella from chickens reacting in the Pullorum-Typhoid agglutination. test. Avian Disease, Georgia, v. 37, p. 805-810, 1993. 